\title{
Risco e Sinthome: A Psicanálise no Sistema Socioeducativo
}

\author{
Andréa Maris Campos Guerra ${ }^{1}$ \\ Cristiane de Freitas Cunha \\ Maria Helena Costa \\ Thaís Limp Silva \\ Universidade Federal de Minas Gerais
}

\begin{abstract}
RESUMO - Pretendemos discutir a aplicação da teoria psicanalítica às políticas públicas voltadas à socioeducação de adolescentes autores de ato infracional. Partimos de revisão sobre adolescência e clínica psicanalítica, especialmente com adolescentes infratores. Com discussão de caso de uma adolescente em cumprimento de medida socioeducativa de liberdade assistida, levantamos duas considerações sobre a psicanálise nesse dispositivo: a singularidade do caso face ao universal da regulação jurídica e os limites e as potencialidades do atendimento institucional. Concluímos pela importância da palavra e pelo recolhimento de seu excedente no trabalho subjetivo do adolescente, verificando a necessidade de ações que encaminhem os efeitos das intervenções. Podemos dizer que o efeito político-social esperado pela aplicação de uma medida socioeducativa não caminha sem a consideração do mais singular e íntimo de cada adolescente, do qual sua posição subjetiva faz testemunho, delimitando seu modo de fazer exceção à regra e habitar o mundo.
\end{abstract}

Palavras-chave: adolescência, clínica psicanalítica, infração, medida socioeducativa, feminilidade

\section{Risk and Sinthome: Psychoanalysis in the Socio-educational System}

\begin{abstract}
We intend to discuss the application of psychoanalytic theory to public policies towards delinquent adolescents. We start from a review of adolescence and psychoanalytic practice, especially with young offenders. With a case of a teenager in under socio-educational measure in assisted liberty, two considerations raised about psychoanalysis in this service: the uniqueness of the case against the universal legal regulation, as well as limitations and potential of institutional care. We conclude by the importance of the word and the gathering surplus in the subjective labor of the adolescent and finally, we see the need for actions that forward the effects of interventions. We state that the expected social-political effect of applying an educational measure needs to consider the uniqueness of each teenager, of which his or her subjective position is testimony, delimiting a way of being an exception to the rule and inhabiting the world.
\end{abstract}

Keywords: adolescence, psychoanalytic clinical, offense, socio-educational measure, muliebrity

Neste artigo, partimos de uma breve localização da orientação psicanalítica freudo-lacaniana na clínica com adolescentes, discutindo mais longamente esse "tempo de despertar" (Lacan, 2003a) e suas idiossincrasias. Interessanos especialmente a experiência com adolescentes infratores, motivo pelo qual, na sequência do artigo, abordamos suas peculiaridades. Finalmente, após a discussão de um caso atendido em medida socioeducativa de liberdade assistida, levantamos duas considerações sobre a presença da psicanálise nesse dispositivo: o destaque da singularidade de cada caso face ao universal da regulação jurídica e os limites e as potencialidades do atendimento institucional. Concluímos relevando a importância da palavra, e o que dela escapa, na localização e mudança de posição subjetiva do adolescente, notadamente autor de ato infracional.

O encontro com o real, entendido em psicanálise como o irredutível à linguagem, se dá em todos os momentos da vida do sujeito, no entanto, a puberdade aparece como um momento paradigmático desse encontro. Nele, o sujeito adolescente precisará criar uma solução própria para lidar

1 Endereço para correspondência: Universidade Federal de Minas Gerais - Faculdade de Filosofia e Ciências Humanas. Avenida Antônio Carlos, 6627, sala F4030, Pampulha, Belo Horizonte, MG, Brasil. CEP: 31270010.E-mail: andreamcguerra@gmail.com com o não saber fazer com essa dimensão real que emerge a partir do corpo. Em psicanálise, chamamos de sintoma essa solução, considerando que o sintoma é uma situação conflitiva na qual simultaneamente realiza-se uma defesa e um desejo (Freud, 1917/1976). Essa solução implica um arranjo, uma composição ou um estilo de resposta que marca o ponto em que o sujeito não se adequa à civilização e tampouco resolve plenamente seu embaraço com o corpo sexuado. A peça de Wedekind (1973) "O despertar da primavera", deixa clara a forma como cada personagem adolescente que compõe a história, fará para lidar com a sexualidade que emerge - o que atualiza a peça, tornando-a um clássico.

A latência, tempo lógico anterior à explosão da puberdade, é, por excelência, um tempo de espera, de fantasia e sonhos que antecederiam à possibilidade do ato sexual. Na contemporaneidade, podemos ver claramente um achatamento do período de latência, principalmente quando se trata dos adolescentes nomeados de infratores. Com eles, os atos, muitas vezes, vêm antes das palavras e de alguma elaboração.

Da mesma forma que cada adolescente amarrará sua resposta sintomática para lidar com o real que irrompe com a puberdade, cada um direcionará seu sintoma para quem o acolha, podendo ser desde um analista a uma instituição. E, considerando o envolvimento com a criminalidade como 
uma possível formação sintomática para o adolescente, trabalharemos aqui com um caso clínico, atendido na medida socioeducativa de liberdade assistida, oferecendo ao sujeito um acolhimento ao seu sintoma, para além dos protocolos normativos. Veremos também como a feminilidade pode causar embaraço a uma adolescente. A puberdade é o momento de "todos os possíveis" (Stevens, 2004, p. 28), e é compartilhando dessa posição que este texto se apresenta.

\section{Psicanálise com adolescentes}

Stevens (2004) nos orienta que o púbere tem que lidar com a emergência do real do corpo, manifestada pelas mudanças corporais que levam a uma maturação sexual. A fim de lidar com essa manifestação do real, que nos aparece como aquilo sobre o qual não há saber pré-estipulado, cria-se um sintoma. Essa resposta, construída a partir da estrutura do sujeito, é resultante da "inscrição dos significantes primordiais, a constituição do fantasma fundamental e o encontro com um mito - o de Édipo, constituindo o inconsciente como sede do sujeito" (Bernardino, 2004, p. 39).

Sabemos que Freud (1996), nos Três Ensaios sobre a Teoria da Sexualidade, escreveu sobre a puberdade dando ênfase às mudanças corporais, como crescimento das gônadas e aumento no nível de hormônios. Mesmo assim, admite a insuficiência dessa explicação, já que a libido não emanaria somente dos órgãos sexuais, mas de todo o corpo, admitindo, então, a hipótese de uma sexualidade original e polimorficamente perversa, que se organizaria nessa época. O real que surge na puberdade não corresponde, portanto, apenas às mudanças biológicas ou ao aparecimento brusco hormonal, mas também à modificação imaginária do corpo, isto é, à modificação real da imagem (Stevens, 2004). Essa imagem é constituída desde sempre por um investimento que não é instintivo e pré-programado, mas, ao contrário, é antecipada através da relação com a alteridade, conferindo um contorno ao corpo antes mesmo da sua integralização motora. Trata-se da operação estrutural denominada por Lacan (1998a) como estádio do espelho, em que se considera a eterna instabilidade da imagem, independente da fase de vida do sujeito.

O corpo, portanto, possui sempre dimensões outras que a fisiológica. Constituído a partir da alteridade, encontra-se desdobrado especularmente e articulado simbolicamente para fazer face ao real. Em distintos momentos da experiência de vida do falasser, assim como na puberdade, essas diferentes dimensões do corpo são convocadas quando do confronto com certa falta de saber lidar com suas novidades. Então, em resposta a esse furo no real, faz-se um sintoma através da substituição metafórica do substrato sem sentido por uma formulação articulada da posição subjetiva do sujeito. Esse sintoma não está somente no campo do simbólico, ou seja, não se autoriza só por ele, mas também faz referência à forma de gozo que escapa à compreensão do sujeito (Alberti, 2009). Por conta desses diferentes registros do corpo, real, simbólico e imaginário, um jovem franzino pode sentir-se forte e poderoso com uma arma na mão ou uma jovem anoréxica pode sentir-se gorda em seu corpo esquálido.
Lacan (2003a) trata do tema da adolescência no prefácio que fez à peça teatral "O despertar da Primavera" de Frank Wedekind (1973), que aborda a adolescência e o impasse a que o sexual dá origem. As histórias do jovem Melchior, enviado pelos pais a uma casa de correção devido à morte da namorada resultante de um aborto e a de Moritz, seu amigo, que se suicida, mostram formas distintas de resposta dos personagens no encontro com o sexual. Trata-se de escolhas, não sem conflitos, ante o pulsional avassalador e o meio, pois, segundo Freud (1932/1997), a sexualidade está aí desde o começo da vida, mas não a consciência moral, que se agrega em nós somente mais tarde. Ao comentar a peça, Lacan (2003a) destaca que a sexualidade faz furo no real, como descoberto por Freud, e se revela traumática, como antecipa Wedekind. É à sexualidade que Lacan (2003a) se refere quando afirma existir algo de que ninguém escapa ileso, e, ainda, e mesmo assim, "'as pessoas não se preocupam com o assunto" (p. 558).

Freud (1923/1997) ressalta o fato de as pulsões eróticas serem, em geral, mais plásticas, desviáveis e deslocáveis que as de destruição, o que nos leva a pensar a clínica sob dois aspectos. $\mathrm{O}$ primeiro refere-se ao analisante e à possibilidade de interpretação de seu sintoma; e o segundo, questiona se o que resta de gozo não traduzido no sinthoma do falasser não marcaria exatamente o modo absolutamente próprio e singular de sua presença no mundo. A noção lacaniana de sinthoma se fundamenta no conceito freudiano de pulsão. Para Freud, o movimento pulsional atua como desvelador de sintomas que exclue qualquer lesão de ordem física, nos quais é possível observar uma série de distúrbios psíquicos. Como uma força que se desloca, a pulsão se organiza segundo seus dois elementos: a representação e o afeto, que lhe é compatível. Funções somáticas se estruturam em razão de um circuito psíquico a transformar algo puramente biológico em psíquico, deixando à mostra um resto inassimilável do pulsional, por isso sem representação.

Enquanto em Freud (1923/1997) o sintoma é abordado como um derivado do trabalho do inconsciente, e a ênfase é dada à singularidade desse movimento, relacionado à sexualidade infantil e ao que dali advém das vivências alteritárias das quais emanam as pulsões eróticas e destrutivas; a questão do falasser é que se torna central na teoria lacaniana, por descrever como o movimento pulsional encontra no significante via real, um operador capaz de trazer a dimensão de um irrepresentável, carregado de gozo. Quanto ao irrepresentável, Miller (2010) distingue o inconsciente real de Lacan do inconsciente transferencial de Freud. Neste, o inconsciente tem sentido e se interpreta, ao passo que naquele, sentido e interpretação se apagam. O real é o que se deposita sobre a exclusão de todo o sentido, sendo o inconsciente real um inconsciente sem recalque.

Lacan (2007), ao pensar a face do gozo do sintoma do lado da letra, fora do corpo, mas não sem o corpo, produz uma mudança teórica. Do postulado do inconsciente estruturado como uma linguagem ou do inconsciente como discurso do Outro, introduz o neologismo apalavra, que se trata da função da fala, vista a partir do real (Miller, 2010). O significante sinthoma, assim, é criado para se referir não a uma formação do inconsciente, mas ao que há de singular em cada um e, ao lado da noção de letra, possibilita o deslocamento da prática 
psicanalítica para o registro do Um, disjunto do Outro. Daí também Lacan deslocar a noção do sujeito, indicando que, em seu lugar, deve vir a noção de falasser, desalojando assim o Outro. Da energética freudiana, Lacan (2007) traz a figuração da cadeia borromeana, na qual introduz uma escrita, autônoma em relação à fala, apresentada pelo sinthoma. $\mathrm{O}$ sinthoma, ao tocar de forma singular o gozo de cada um, acha-se remetido então ao sexual como originário e ao real em ato. Daí Lacan (1988) precisar que "a interpretação não se dobra em todos os sentidos" (p. 198), mas recai sobre o objeto pulsional e o objeto causa do desejo.

Então, uma característica particular se destaca na clínica psicanalítica: a cura não se sustenta a partir de uma resolução sintomática, pois o sintoma para o sujeito é, a ele, muito caro; é o que lhe garante originalidade. Em suas diferentes manifestações (toxicomania, grupalidade, inscrição no crime, apego aos estudos, etc.), torna-se uma via de solução temporária que sustenta uma solução subjetiva estrutural.

Espera-se, assim, que o adolescente possa conferir uma nova interpretação à herança simbólica advinda da relação com o pai, que orienta sua forma originária de satisfação e gozo. E também, para além dessa dimensão simbólica, que possa tratar o que resta do pai, o real do pai, não inscrito na metáfora paterna (Porge, 1998). Enquanto o adolescente faz questão de afirmar a originalidade de seu sintoma, o analista se empenha na tarefa de demonstrar a ele que todo sujeito pode recolher do sinthoma outros usos e outras modalidades de satisfação. Há, pois, por um lado, a urgência e o risco desse tempo de passagem e, por outro, a configuração ética que determina sua solução estrutural. Com adolescentes infratores, no qual a pressão social se dá na direção da ortopedia do comportamento, é fundamental destacar a dimensão contingente e singular de suas soluções. Entendamos um pouco mais essa lógica.

\section{Sobre os adolescentes em conflito com a lei}

No caso dos jovens atravessados pela experiência do tráfico de drogas em especial, notamos uma precocidade com relação a sua entrada na vida adulta ou mesmo uma supressão desse compasso de espera, que implica o trabalho realizado pela adolescência em resposta à puberdade (Guerra, Soares, Pinheiro, \& Lima, 2012). Ao contrário do que comumente se observa na dilatação da adolescência que caracteriza a contemporaneidade, podemos dizer que esses jovens passam pela puberdade, mas não pela adolescência.

Se a puberdade é um fenômeno universal, o termo adolescência é uma invenção social. Segundo Calligaris (2000), o termo não apresenta uma definição clara, e essa indefinição acaba por instaurar nessa fase da vida uma moratória forçada, pois não se sabe exatamente o que esperar do adolescente para que ele possa exercer seus papéis na sociedade. Esse adiamento ou prorrogação da assunção da vida adulta, sem dúvida, se deve a um adiamento da entrada na vida economicamente produtiva por questões de equilíbrio de mercado. Subjetivamente, entretanto, implica em uma dilatação imposta socialmente, que acaba por se constituir em um tempo de experimentação subjetiva diante das novidades advindas da puberdade face às soluções infantis.

Como em nossa cultura não existem rituais de passagem que marquem a saída da infância e a entrada na fase adulta, a adolescência opera como um período intermediário, de moratória (Calligaris, 2000), no qual o adolescente adia sua inserção no mundo adulto, preparando-se para ela. Apesar de apresentar todas as condições para o exercício da vida sexual, profissional e afetiva, a sociedade não permite que ele exerça esses papéis. A fase da adolescência é, pois, marcada por uma espécie de não-lugar, um intervalo, um período de espera para a entrada no mundo social. Se esse período de moratória imposto socialmente pode dificultar a inserção social do jovem, sabemos que um intervalo entre o despertar do real da puberdade e a assunção de uma posição sexuada se faz estruturalmente necessário.

Assim, esse adiamento acaba por convocar a elaboração púbere, levando o jovem a se decidir quanto às suas escolhas. As exigências de constituição da posição sexuada, envolvendo o enfrentamento de seu destino, faz com que o adolescente recorra às fantasias como forma de compor uma resposta à falha estrutural de saber sobre o real sexual que se apresenta a ele. Entretanto, com jovens qualificados infratores, parece existir uma redução desse intervalo.

A construção da fantasia como resposta ao que surge enigmático no campo do Outro, por um lado, envolve um recobrimento da castração e, por outro lado, envolve uma construção própria, que leva o púbere à separação da posição de objeto da fantasia materna. Ao construir uma resposta fantasmática ao enigmático desejo do Outro, o sujeito tece o seu destino. Barros (1996) ressalta a dimensão paradoxal da fantasia: ela só é possível a partir da separação, ao mesmo tempo em que tenta encobrir o que provocou a separação, ou seja, o que se revelou como opaco no próprio gozo do sujeito e no desejo do Outro. Assim, há na adolescência a possibilidade de um encontro que rompe a continuidade edipiana, pois o sujeito, ao se confrontar com aquilo que escapa à determinação significante, ou seja, seu gozo desconhecido, pode se responsabilizar por essa nova forma de gozar (Lima, 2003).

No momento do despertar da puberdade, os jovens em conflito com a lei passam a ter acesso fácil à vida sexual, ao crime e às drogas, que oferecem uma solução rápida e eficaz para o encobrimento do fato de que há falta, o que é estrutural. Ao despertarem do sonho da infância são subtraídos, enquanto sujeitos, pela ilusão capitalista de uma solução, orientada pelo Outro do crime, visto que a figura do Outro está encarnada nos chefes da criminalidade. As normas do crime, encarnadas nas lideranças sob a forma de ordens de ferro - o que chamamos de Outro do crime - se oferecem como vetores de orientação para o gozo adolescente. Logo, ao entrar na puberdade, quando a escolha de objeto e de uma posição sexuada ainda não estão definidas, muitos desses jovens já se tornam pais, passam a viver com uma companheira, abandonam os estudos e, por vezes, se instalam no circuito do crime. As exigências impostas pelas condições de vida desses jovens forçam uma urgência de resposta do sujeito, constituindo um estilo adulto de funcionar no mundo, sem o tempo de elaboração dessa posição. Os jovens em conflito com a lei parecem identificar-se imaginariamente 
aos ideais do crime, adotando o estilo de vida daí decorrente, sem realizar a passagem simbólica que lhe conferiria a configuração de uma resposta aos impasses da puberdade. Com isso, resta em aberto uma escolha orientada pelo desejo.

Ao se deparar com o que faz furo no saber, o sujeito adolescente precisa construir novo saber sobre si que possibilite alojar o seu gozo e sustentar seu desejo. Para isso, é necessário esse compasso de espera para que o sujeito possa construir sua resposta, compor o arranjo com o qual organizará sua existência, sua relação com o mundo e com o gozo. Diante dessa falha de saber no real, que se presentifica para todos, a trajetória de alguns jovens parece conduzi-los a estratégias de inscrição - e não de segregação - no laço social pela via do crime.

Nesse sentido, diante de fenômenos característicos da puberdade - como o esfacelamento da imagem, a impossibilidade simbólica de dizer das mudanças físicas e afetivas, e do real que irrompe com o encontro com a sexualidade (ou castração) -, o saber do crime poderia ser pensado como um Outro que garante uma resposta e uma inscrição no laço social. E, na medida em que inclui atos agressivos em sua composição, pode ainda se configurar em uma via suplementar de escoamento pulsional. Pressupomos, pois, que o jovem, na busca de afirmação de si, tempo da reafirmação de posições e escolhas, endereça-se a um Outro do saber (mundo do crime), identificando-se com ele - complementarmente podendo fazer desse arranjo uma solução para o excedente pulsional que o atravessa. O Outro do crime é promessa de resposta ao furo da estrutura, pois oferece um sistema normativo e regulador, ainda que não dialetizável, que funciona como contorno ao real pulsional em jogo na puberdade (Guerra et al, 2009).

Essas são questões fundamentais para se pensar, tanto a direção do tratamento psicanalítico a ser oferecido para esses adolescentes, como sua implicação e responsabilização quanto ao ato infracional. Se toda escolha é forçada, para a psicanálise, aqui a "cola" com o discurso do Outro do crime parece favorecer uma desimplicação do sujeito com as decisões que orientam sua posição no crime. Diante desses pressupostos, a psicanálise pensa e articula as especificidades da clínica com o adolescente e contribui com o funcionamento das medidas socioeducativas.

A demanda dos adolescentes em envolvimento com a criminalidade e/ou cumprimento de medida socioeducativa é uma demanda ética, no sentido de que ele precisa reunir elementos que sustentem uma forma de resposta, entendida aqui enquanto possibilidade de responsabilização. Se ele não consegue mais recorrer aos recursos de que dispunha na infância para se satisfazer, nem contar com o saber originário dos pais, precisará reinstaurar um tempo de elaboração e ciframento das escolhas que fez até então. Enquanto ser de linguagem, qualquer jovem encontrará sempre um obstáculo representacional para articular sua posição simbólica diante dessa falta de saber. Ele sabe que nem a ele, nem ao adulto, tudo é outorgado, ou seja, há limites sempre - advindos dessa condição de sujeito sexuado inscrito na linguagem.

Finalmente destacamos que a função de uma análise não pode corresponder a uma expectativa idealista, que contemple a noção de bem-estar biopsicossocial ou de adaptação, mas direciona-se para uma mudança de posição diante daquilo que é imutável, ou seja, o encontro do corpo com a linguagem. Nossa direção, então, é a de que o adolescente possa, a partir de um novo saber, responsabilizar-se por outras soluções, experimentando-se de outra maneira, diferente da lógica predicativa que o instala no campo da infração. $\mathrm{Ou}$, nas palavras de Lacadée (2011), apostamos que ele possa encontrar "a fórmula e o lugar" (p. 32) para sua presença no laço social.

\section{Um caso no sistema socioeducativo}

O Estatuto da Criança e do Adolescente - ECA, promulgado em 1990, regulamenta a situação infanto-juvenil no Brasil, regendo-se pela doutrina da proteção integral às crianças e aos adolescentes. Seu quarto capítulo é dedicado às medidas socioeducativas, que podem ser aplicadas ao adolescente quando do cometimento de um ato infracional, entendendo este como conduta análoga ao crime ou à contravenção penal.

Após a apreensão do adolescente e realizados os procedimentos legais, o juiz da Vara da Infância e da Juventude pode aplicar uma das medidas socioeducativas previstas no ECA: advertência, obrigação de reparar o dano, prestação de serviço à comunidade, liberdade assistida, semiliberdade e internação em estabelecimento socioeducativo. Com isso, os psicanalistas que atuam no atendimento socioeducativo precisam reinventar sua prática para atender às demandas surgidas a partir do atendimento ao adolescente em cumprimento de medida, com vistas ao que rege o ECA: responsabilização pelo ato infracional cometido e reinserção sociofamiliar. Obviamente essa mudança de posição no plano sociopolítico não se faz sem uma implicação subjetiva do jovem em relação a seu ato.

A partir da prática junto à medida de liberdade assistida (LA), discutiremos um ponto específico do atendimento das adolescentes mulheres que têm se mostrado como um desafio. Algumas adolescentes que chegam para o cumprimento da medida, apreendidas por tráfico de drogas, trazem como justificativa para sua inserção na criminalidade, o relacionamento amoroso com um jovem já envolvido com essa atividade ilícita. Identificam-se como "mulher de bandido" enquanto solução ao impasse da feminilidade advindo da puberdade e, dessa forma, se desresponsabilizam pelo ato cometido, desimplicando-se dele.

Esses relacionamentos são notadamente marcados pela violência, chegando ao que poderíamos nomear como devastação. Lacan (2003c) define a devastação a partir da relação primeva da menina com sua mãe, afirmando que ela se instala quando a mulher se coloca como objeto do parceiro na relação amorosa, não conseguindo fazer a mediação com ele pela via do semblante. Muitas vezes identificada ao significante "mulher de bandido", as adolescentes infratoras não conseguem se inscrever no feminino a partir de outra ordem. Dessa forma, o que se coloca como um desafio é saber como operar com elas quando a infração parece caminhar lado a lado com a própria dificuldade de se saber o que é ser uma mulher. Em outras palavras, quando a dimensão pública (política) e a vida íntima (aqui inconsciente) confluem para a composição de uma posição no laço social pela via do crime. 
Para esse fim, trabalharemos a partir do fragmento do caso clínico de uma adolescente de 15 anos, atendida na medida de LA, cuja entrada na criminalidade se deu exatamente pela via da parceria amorosa. A complexidade do caso radica no fato de que essa adolescente, além do parceiro criminoso, possui uma irmã que é líder do tráfico em sua região, parecendo encarnar para ela a resposta ao furo real no saber sobre o feminino. Por fim, o pai, traficante e usuário, fornece elementos para uma identificação masculina, perspectiva a partir da qual a jovem intenta saber o que é uma mulher. Dessa maneira, ela parece criar um obstáculo à construção sobre sua feminilidade, congelando-se na identificação imaginária à "infratora" ou à "mulher de bandido", ali onde falta um referente sobre o que é ser uma mulher. Parece não querer saber nada disso, instalando-se no risco dessa posição alienada.

Vejamos o caso. Amanda ${ }^{1}$ reiniciou diversas vezes o cumprimento da medida. Ela residia apenas com a mãe, e o pai era traficante e usuário de drogas em outro bairro. Sua irmã mais velha atualmente está presa por tráfico de drogas juntamente com o marido, e era conhecida como a chefe do tráfico de drogas local. Amanda foi apreendida pela primeira vez por tráfico de drogas, portando grande quantidade de drogas destinada à venda. Ela havia parado de estudar no início do ensino fundamental e não estava estudando regulamente há algum tempo.

Sobre sua apreensão por tráfico, disse que as drogas eram do namorado e que foi apreendida por causa dele. Ela chegou a morar com ele, começando a traficar com e para ele, apresentando dificuldades em falar sobre esse relacionamento. Tentava se desresponsabilizar pelo envolvimento com o tráfico, sempre jogando para o namorado essa responsabilidade. Dizia apenas: "comecei a vender por causa dele".

A genitora queixava-se de que Amanda "só queria ficar na rua, fumando maconha com as amigas". Ela não interveio quando Amanda decidiu morar com o namorado, aos 14 anos de idade, apenas queixando-se da situação para a analista. Mostrou-se apática e cansada, não se envolvendo no acompanhamento da medida de LA da filha. A relação entre elas era pautada e marcada pela agressividade e Amanda queixava-se que ela sempre a cobrava por ter ido morar com o namorado, ter se envolvido com drogas e com o tráfico, bem como por ter abandonado a escola.

Sobre o pai, Amanda disse-nos que ele era usuário de drogas e que também traficava, mas quase que exclusivamente para manter seu vício. Quando perguntada se o pai auxiliava na manutenção da casa, Amanda dizia que não, porque ele não "tinha dinheiro nem para ele mesmo". O pai apresentava-se fraco e incapaz de auxiliar na manutenção da própria família. A mãe referia-se ao ex-companheiro como um fracassado, um "viciado em drogas", e como alguém que nunca conseguiu desempenhar o papel de mantenedor da família. O fato de o pai ser envolvido com a criminalidade não parecia ser um incômodo para a família, mas sua incapacidade em mantê-la sim. Dessa forma, até em seu envolvimento com o crime, o pai era um fracassado.

1 Alteramos o nome da adolescente de forma a preservar sua identidade.
Amanda demandava voltar a estudar, fazer cursos, passeios, mas não sustentava nenhum dos encaminhamentos para isso, esvaziando qualquer movimento mínimo de engajamento subjetivo com seu ato de fala. Quando ela se mantinha frequente aos atendimentos, períodos em que era possível trabalhar com ela sobre o cumprimento da medida, ou quando algum encaminhamento solicitado era efetivado, ora ela era novamente apreendida, ora voltava a descumprir a medida, indicando assim uma dificuldade em encerrar a medida aplicada. Dessa forma, quando se começava a costurar com a adolescente alguma possibilidade de se caminhar para o encerramento da medida, ainda que muito aquém do ideal objetivo proposto pelo ECA, Amanda, de alguma forma, atuava novamente e acabava sendo apreendida ou permanecia inacessível às formas de marcação de atendimento.

No último retorno ao cumprimento da medida, sua irmã havia sido presa por tráfico de drogas com o marido e Amanda apresentava-se triste e abalada com a situação, mas se mantinha calada e ríspida. Em um determinado atendimento ficou nervosa com a técnica, quando esta lhe perguntou se havia ido ao Juizado para uma audiência que já estava há meses marcada: "Se eu tiver que ficar indo lá, não vou aguentar, vou fazer uma besteira!", gritou. Nesse atendimento, Amanda se propôs a falar do ato infracional e conversar sobre os eixos da medida. Falou do namoro e como o mesmo foi marcado pela agressividade. No entanto, dizia, um pouco orgulhosa, que mesmo o namorado tendo várias outras mulheres, ela era a única que residia com ele, na época de seu namoro. O namoro só terminou quando o namorado foi expulso do bairro por outros traficantes e, dessa forma, Amanda foi abandonada. Não parecia haver para ela problemas durante o namoro, a violência não parecia ser na época uma questão. É justamente no momento em que foi abandonada, que Amanda ficou sem referencial.

Com a prisão da irmã e a expulsão do companheiro, caíram os semblantes vinculados ao crime que funcionavam como anteparo identificatório à questão sobre o que é ser uma mulher nessa passagem adolescente. O pai, fracassado, também não sustentava um semblante que permitia a construção de uma resposta acerca da posição feminina. Com essa queda, abriu-se uma nova via para que Amanda se interrogasse sobre sua posição subjetiva e sua causa, que a condenavam ao percurso infracional, muito antes do sistema socioeducativo alocá-la e reconhecê-la nele.

\section{A prática do psicanalista no atendimento de adolescente sob medida de liberdade assistida}

\section{O singular no universal}

Como se depreende do caso, é no ponto em que a exceção do sujeito ou sua mais absoluta singularidade comparece no cenário institucional que ele pode ser tomado em trabalho. Qualquer proposta que vise ao engajamento do sujeito face ao ato infracional cometido deverá, assim, localizar qual a função que esse ato possui em sua dinâmica psíquica. Como lembra Lacan (2003b), a realidade humana não é apenas obra da organização social, mas é uma relação subjetiva que, 
por estar aberta à dialética patética que tem de submeter o particular ao universal [culmina em] dolorosa alienação e encaminhamento nas represálias da agressividade.

Nesse sentido, ainda que a aplicação da medida esteja prevista para todos, será da singularidade da construção do caso que retiraremos os vetores para a direção do trabalho, suspendendo o circuito repetitivo do gozo que convoca o sujeito a retornar sempre à mesma posição. Nesse sentido, o caso de Amanda nos ensina que a responsabilização exige um trabalho subjetivo, já que "por nossa posição de sujeito, sempre somos responsáveis” (Lacan, 1998b, p. 873).

Na construção de sua feminilidade, a puberdade convoca Amanda a uma resposta sobre o que é ser uma mulher, ao que ela responde recorrendo às insígnias a ela disponibilizadas: uma irmã criminosa (que talvez opere como anteparo identificatório sobre o que é ser mulher), um pai criminoso (que não alimenta uma identificação fálica, mas talvez o desejo de reparação face a seu fracasso) e o namorado (que a elege, assinalando sobre seu ser um "a mais", que a diferencia das outras mulheres, ainda que ao preço de sua subjugação e violência, talvez alimentadas pelo masoquismo feminino). A mãe, que não transmitia os atributos da feminilidade (não era vaidosa, não tinha um companheiro), não demonstrava ser desejante e nem desejável, não parece resguardar um campo enigmático que propulsionaria Amanda à construção de uma resposta a esse enigma. Além disso, Amanda parecia repetir a história da mãe, se envolvendo com um pequeno traficante que também a abandona, mostrando assim um laço identificatório com a genitora.

A partir do que foi abordado, podemos interrogar se é possível tratar a dimensão infracional do seu ato e sua responsabilização, sem considerar essa constelação de elementos de identificação e de meios de gozo? A medida teria efetividade sem esse trabalho?

\section{Os limites e as potencialidades do atendimento de orientação psicanalítica na instituição.}

O fato de se tratar de um atendimento inserido numa instituição, cujo valor primeiro é socioeducativo, torna necessário que as coordenadas do trabalho, recolhidas das soluções inventadas pelos adolescentes, possam encontrar lugar dentro da oferta de recursos da instituição e dentro de seu funcionamento. Nesse sentido, cabe lembrar que, num primeiro plano, toda instituição possui uma dimensão social e jurídica clara, a ela sendo acrescida a possibilidade de uma dimensão de vida, que possa produzir efeitos sobre o sujeito (Laurent, 2007). Assim, pensando a instituição como comunidade de vida com funções específicas destinadas a atender o plano social, e nessa instituição em particular que é determinada pelo ECA, consideramos que seja preciso localizar o modo como o sujeito repete na instituição seu meio de gozo, donde o sintoma torna-se o índice de orientação no trabalho institucional, quando realizado a partir da psicanálise, pois é com ele que o sujeito se apresenta em sua causalidade e pode, então, se responsabilizar por sua condição.

Pois bem, que uso Amanda faz da medida de LA? Por que sempre que lhe é oferecida a possibilidade de desvincular-se, ela atua? Por que sempre demanda uma atividade extra para não se vincular a ela? Após a conquista da construção de um espaço de fala, porque Amanda desaparece diante das ofertas de se inscrever em outro plano da cidade?

Parece-nos que o sujeito aí insiste na posição de gozo extraída do lugar alienado ao ideal do crime. É uma posição de gozo da qual Amanda não quer recuar, não quer abrir mão. É preciso que ela encontre novas e outras vias de ocupação da posição feminina - diferente da "mulher de bandido", agora esvaziada - para que possa se deslocar politicamente da posição de "infratora". No momento em que a prisão da irmã e o abandono do namorado assinalam um fracasso dos ideais, Amanda se devasta ao precisar se haver com os furos que o mundo do crime até então tamponou. No vazio legado por essa queda, abre-se uma hiância que permite à instituição intervir e a Amanda colocar palavras onde antes havia a reticência, e agora o choro repentino e imotivado.

\section{Considerações Finais}

Podemos dizer que o efeito político-social esperado pela aplicação de uma medida socioeducativa não caminha sem a consideração do mais singular e íntimo de cada adolescente, do qual sua posição de falasser faz testemunho e delimita seu modo de fazer exceção à regra e habitar o mundo. Há uma torção que nos permite atuar no ponto em que a dimensão política, determinada pelos fatores materiais e econômicos, e a dimensão subjetiva, determinada pelo inconsciente, tornam-se o lado direito e o avesso de uma mesma posição de gozo. Na torção entre os dois planos, a partir de um ponto de perda, os acontecimentos poderiam determinar tomadas de posição que alterariam a rota do sujeito no laço social, interferindo nas respostas que ele constrói ao longo de sua vida (Guerra \& Martins, 2013).

Mostramos como Lacan, conduzido pela via freudiana do Além do Princípio do Prazer (1920/1999), destacou os efeitos possíveis de criação na pulsão de morte e destrutividade. Permitindo relacionar a leitura do ato infracional à categoria de laço social, inscrevendo-o, dessa forma, numa dimensão sociopolítica, impensável antes do discurso analítico. Essa leitura psicanalítica, no âmbito das instituições, viabiliza a possibilidade de se atuar nos atendimentos, cientes de que existe no ato infracional algo do singular do gozo de cada um, partindo-se do pressuposto de que há satisfação pulsional nos atos humanos, sejam eles impulsos amorosos e/ou destrutivos.

No caso aqui apresentado, tentamos fazer ver um modo de operação em que o movimento da fala revelou o vivente em sua posição subjetiva, bem como a Vida, que está para além da vida biológica - movimento que fundamentalmente passa pela linguagem, conforme nos ensina a psicanálise. $\mathrm{O}$ recolhimento desses efeitos, através das redes de trabalho junto ao sistema socioeducativo, aponta a necessidade de endereçá-los e acompanhá-los ao longo do processo. Inventar-se implica um efeito de sujeito, com consequências em sua posição política e jurídica no laço social e na responsabilidade pelo ato, por qualquer ato de fala, como horizonte ético. 


\section{Referências}

Alberti, S. (2009). Esse sujeito adolescente. Rio de Janeiro: Contra Capa.

Barros, M. R. C. R. (1996). Adolescência: quê despertar? In H. C. Ribeiro, \& V. Pollo (Eds.), Adolescência: o despertar (pp. 69-80). Rio de Janeiro: Contra Capa.

Bernardino, L. M. F. (2004). As psicoses não-decididas da infância: um estudo psicanalítico. São Paulo: Casa do Psicólogo.

Calligaris, C. (2000). A adolescência. São Paulo: Publifolha Estatuto da Criança e do Adolescente. Lei 8069 de 13 de julho de 1990. Retrieved from http://www.planalto.gov.br/ccivil_03/ leis/L8069.htm

Freud, S. (1999). Más allá del principio de placer. In J. L. Etcheverry (Trad.), Más allá del principio de placer, Psicología de las masas y análisis del yo y otras obras. ( 8 a edição) (vol. 18., pp. 1-62). Buenos Aires: Amorrortu. (Trabalho original publicado em 1920)

Freud, S. (1997). Conferência 31: La descomposición de la personalidade psíquica. In J. L. Etcheverry (Trad.), Nuevas conferencias de introducción al psicoanálisis y otras obras. (5 edição) (vol. 22, pp. 53-74) Buenos Aires: Amorrortu. (Trabalho publicado originalmente em 1932)

Freud, S. (1997). El yo y el ello. In J. L. Etcheverry (Trad.), El yo el ello y otras obras. (7a edição) (vol 19., pp. 3- 66) Buenos Aires: Amorrortu. (Trabalho original publicado em 1923)

Freud, S. (1996). Três ensaios sobre a teoria da sexualidade: transformações da puberdade. In J. L. Etcheverry (Trad.), Edição standard brasileira das obras psicológicas completas de Sigmund Freud. (v. 7., pp. 196-217) Rio de Janeiro: Imago (Trabalho original publicado em 1905)

Freud, S. (1976). Conferência XVII O sentido dos sintomas. In J. L. Etcheverry (Trad.), Edição standard brasileira das obras psicológicas completas de Sigmund Freud. (v. 16. pp. 305322) Rio de Janeiro: Imago (Trabalho original publicado em (1916-1917 [1915-1917])

Guerra, A. M. C., \& Martins, A. S. (2013). Subjetividade e política: Psicanálise e Intervenção com Jovens em Conflito com a Lei. Manuscrito.

Guerra, A., Soares, C., Pinheiro, M., \& Lima, N. L. (2012). Violência urbana, criminalidade e tráfico de drogas: uma discussão psicanalítica acerca da adolescência. Psicologia em Revista, 18(2), 247-263. doi: 10.5752/P.1678-9563
Guerra, A. M. C., Lima, N. L., Simões, K. S., Freitas, M. C. S., Pompeu, M. X. M., Pechir, N. A. N. . . \& \& Soares, C. A. N. (2009). O desafio do trabalho com jovens envolvidos com a criminalidade: oficinas comunitárias como estratégia inovadora na Justiça Social. Cartas de Psicanálise, v. 2, p. 200-209.

Lacadée, P. (2011). O Despertar e o Exílio: ensinamentos psicanalíticos da mais delicada das transições, a adolescência. Rio de Janeiro: Contra Capa.

Lacan, J. (2007). O seminário, livro 23: o sinthoma. Rio de Janeiro: Jorge Zahar Ed.

Lacan, J. (2003a). Prefácio a O Despertar da Primavera. In Outros Escritos. (pp. 557-559). Rio de Janeiro: Jorge Zahar.

Lacan, J. (2003b). Premissas a todo desenvolvimento possível da criminologia. In Outros Escritos. (pp. 127-131). Rio de Janeiro: Jorge Zahar.

Lacan, J. (2003c). O aturdito. In Outros Escritos. (pp. 448-497). Rio de Janeiro: Jorge Zahar.

Lacan, J. (1998a). O estádio do espelho como formador da função do eu. In Escritos. (pp. 96-103). Rio de Janeiro: Jorge Zahar.

Lacan, J. (1998b). A Ciência e a verdade. In Escritos (pp. 869-892): Rio de Janeiro: Jorge Zahar.

Lacan, J. (1988). O Seminário: Livro 11. Os quatros conceitos fundamentais da psicanálise. Rio de Janeiro: Jorge Zahar.

Laurent, E. (2007). Dois aspectos da torção entre sintoma e instituição. In V. A. Ribeiro (Trad.), Associação do campo freudiano. Pertinências da Psicanálise Aplicada. (pp. 237249). Rio de Janeiro: Forense Universitária.

Lima, N. L. (2003). Fascínio e Alienação no ciberespaço. (Unpublished doctoral dissertation). Universidade Federal de Monas Gerais, Belo Horizonte.

Miller, J. (2010). Perspectivas do Seminário 23 de Lacan - O Sinthoma. Rio de Janeiro: Jorge Zahar Ed.

Porge, E. (1998). Os nomes do pai em Jacques Lacan: pontuações e problemáticas. Rio de Janeiro: Companhia das Letras.

Stevens, A. (2004). Adolescência, sintoma da puberdade: Clínica do contemporâneo. Revista Curinga, 20, 27-39.

Wedekind, F. (1973). O despertar da primavera. Lisboa: Estampa. (Trabalho original publicado em 1891)

Recebido em 06.02.2013

Primeira decisão editorial em 18.06.2013

Versão final em 15.08.2013

Aceito em 19.08.2013 